\title{
Treatment of Strabismus After Retinal Detachment Surgery With Botulinum Neurotoxin A
}

\author{
JOHN LEE, BRIAN PAGE, JONATHAN LIPTON \\ London
}

\begin{abstract}
Summary
Thirty-one consecutive patients were treated with injections of Botulinum Neurotoxin A to rectus muscles for strabismus following retinal detachment surgery. In 14 cases the presenting problem was diplopia and in 17 cases the presenting problem was cosmetic appearance. A total of 67 injections was given. Twenty-seven cases had nine months or more follow-up. Of these, four of 11 cases with diplopia had fusion restored, four were shown to have no fusion potential, and three had temporary improvement only. In 16 cases with a primary cosmetic problem there was no useful effect in two, three had surgery as an alternative, three were realigned long-term, and eight had continuing maintenance therapy with toxin. Over half the series had undergone multiple detachment surgery, often for giant tears and other complex pathology.
\end{abstract}

Ocular motility problems following retinal detachment surgery are not uncommon. Retrospective studies ${ }^{1-t}$ have shown an incidence of up to $14 \%$ of post-operative motility dysfunction, while prospective studies have shown an even higher incidence with up to $73 \%$ of patients showing limited ocular movements in the immediate post-operative period..$^{5-7}$ Several series have correlated persisting ocular motility problems with encirclement, re-operations and large explants especially in contact with rectus muscles.

Little has been written on management of this disabling complication, ${ }^{8-11}$ but there is general agreement that muscle surgery is difficult and may be contra-indicated if there is a risk of redetachment or explant extrusion.

Accordingly, a treatment technique which does not increase muscle fibrosis or disturb explants is an attractive option in such patients. Most of the patients in this series were referred by the specialist vitreo-retinal surgeons at Moorfields Eye Hospital, many being tertiary referrals from other ophthalmic units.

\section{Pre-Injection Findings-Table I}

Thirty-one consecutive patients are reported. All attended the Toxin Clinic for strabismus at Moorfields Eye Hospital between March 1983 and September 1990. The sex ratio was 20 males to 11 females and the age range was from 20 to 73 years with a mean of 43 . Twentysix patients had undergone unilateral retinal reattachment surgery. A single procedure was performed in 13 cases, six had two procedures, three had three, three had four and two had six procedures.

Bilateral detachment surgery had been performed in four cases. Two had one procedure on each eye, one had two and three procedures and one three and four. In one case the details of surgery were not available. There was a high incidence of other pathology. Six 
Table I Pre-injection findings

\begin{tabular}{|c|c|c|c|c|c|c|c|c|}
\hline Case & Age & Sex & Aetiology & $\begin{array}{l}\text { Retinal } \\
\text { Surgery }\end{array}$ & $\begin{array}{c}\text { Strabismus } \\
\text { Surgery }\end{array}$ & $\begin{array}{l}\text { Primary } \\
\text { Problem }\end{array}$ & $B S V$ & Deviation \\
\hline 1. & 20 & $\mathbf{M}$ & Trauma & $\times 1$ & - & Cosmesis & $\mathrm{N}$ & 12XT, 20RHT \\
\hline 2. & 29 & M & $\mathrm{IOFB}+\mathrm{FT}$ & $\times 2$ & - & Cosmesis & $\mathrm{N}$ & $45 \times \mathrm{T}$ \\
\hline 3. & 32 & $\mathrm{~F}$ & Primary & $\times 6$ & - & Cosmesis & $\mathrm{Y}$ & $40 \mathrm{XT}$ \\
\hline 4. & 29 & M & Primary & $\times 2$ & $\times 1$ & Diplopia & $?$ & 50 R hypo \\
\hline 5. & 35 & $\mathrm{~F}$ & Primary & $\times 1$ & - & Diplopia & $\mathrm{Y}$ & $45 \mathrm{ET}$ \\
\hline 6. & 52 & $\mathbf{M}$ & Trauma & $\times 1$ & - & Diplopia & $\mathrm{Y}$ & $25 \mathrm{XT}$ \\
\hline 7. & 72 & $\mathrm{M}$ & Primary & $\times 1$ & - & Diplopia & $?$ & $35 \mathrm{XT}$ \\
\hline 8. & 31 & M & Trauma & $\times 2$ & $\times 1$ & Cosmesis & $\mathrm{N}$ & $25 \mathrm{ET}$ \\
\hline 9. & 68 & $\mathrm{~F}$ & Primary & $\times 1$ & - & $\begin{array}{l}\text { Diplopia } \\
\text { distortion }\end{array}$ & $?$ & $40 \mathrm{XT}$ \\
\hline 10 . & 21 & M & Trauma & $\times 1$ & - & Cosmesis & $\mathrm{N}$ & $18 \mathrm{ET}$ \\
\hline 11. & 37 & M & Cong. Cat. & $\times 1, \times 1$ & - & Diplopia & $\mathrm{Y}$ & $18 \mathrm{ET}$ \\
\hline 12. & 28 & M & $\mathrm{IOFB}+\mathrm{GT}$ & $\times 3$ & - & Cosmesis & $\mathrm{N}$ & $50 \mathrm{ET}$ \\
\hline 13. & 48 & $\mathrm{~F}$ & Cong. Cat. & $\times 3, \times 2$ & - & Cosmesis & $\mathrm{N}$ & $45 \mathrm{ET}$ \\
\hline 14. & 48 & M & Primary & $\times 6$ & - & Diplopia & $\mathrm{N}$ & $30 \mathrm{ET}$ \\
\hline 15. & 60 & $\mathrm{~F}$ & Primary & $\times 3$ & - & Cosmesis & $\mathrm{Y}$ & $25 \mathrm{ET}$ \\
\hline 16. & 51 & $\mathbf{M}$ & n.k. & n.k. & - & Diplopia & $?$ & $35 \mathrm{XT}$ \\
\hline 17. & 73 & $\mathrm{~F}$ & Aphakia & $\times 1$ & - & Cosmesis & $\mathrm{N}$ & $35 \mathrm{XT}$ \\
\hline 18. & 48 & M & IOFB & $\times 2$ & $\times 1$ & Diplopia & $\mathrm{N}$ & $45 \mathrm{XT}$ \\
\hline 19. & 68 & M & DPR & $\times 4$ & - & Cosmesis & $\mathrm{N}$ & $20 \mathrm{ET}, 7 \mathrm{LHT}$ \\
\hline 20. & 38 & M & Aphakia & $\times 1$ & - & Diplopia & $?$ & $25 \mathrm{ET}$ \\
\hline 21. & 33 & M & Trauma & $\times 2$ & - & Cosmesis & $\mathrm{N}$ & $45 \times \mathrm{XT}$ \\
\hline 22. & 21 & $\mathrm{~F}$ & GT & $\times 1$ & - & Cosmesis & $\mathrm{N}$ & $25 \mathrm{ET}$ \\
\hline 23. & 60 & M & Primary & $\times 3$ & $\times 2$ & Cosmesis & $\mathrm{N}$ & $18 \mathrm{ET}$ \\
\hline 24. & 20 & $\mathrm{~F}$ & Bilat. GT & $\times 1, \times 1$ & $\times 1$ & Cosmesis & $\mathrm{N}$ & $60 \times T$ \\
\hline 25 . & 32 & $\mathrm{~F}$ & DPR & $\times 4$ & - & Cosmesis & $\mathrm{N}$ & $35 \mathrm{XT}$ \\
\hline 26. & 38 & M & Primary & $\times 4, \times 3$ & - & Cosmesis & $\mathrm{N}$ & $35 \mathrm{ET}$ \\
\hline 27. & 43 & $\mathrm{~F}$ & DPR & $\times 1$ & - & Diplopia & $?$ & $25 \mathrm{XT}$ \\
\hline 28. & 25 & M & Primary & $\times 1$ & - & Cosmesis & $\mathrm{N}$ & $50 \times T$ \\
\hline 29. & 52 & $\mathbf{M}$ & Primary & $\times 1$ & - & $\begin{array}{l}\text { Diplopia } \\
\text { distortion }\end{array}$ & $?$ & $20 \times T$ \\
\hline 30. & 64 & M & Primary & $\times 2$ & - & Diplopia & $?$ & $25 \mathrm{XT}$ \\
\hline 31. & 58 & $\mathrm{~F}$ & Primary & $\times 1$ & - & Diplopia & $?$ & $45 \mathrm{ET}$ \\
\hline
\end{tabular}

Abbreviations: IOFB = Intraocular foreign body

$$
\begin{aligned}
\mathrm{GT} & =\text { Giant retinal tear } \\
\mathrm{DPR} & =\text { Diabetic proliferative retinopathy } \\
\mathrm{ET} & =\text { Esotropia } \\
\mathrm{XT} & =\text { Exotropia } \\
\mathrm{HT} & =\text { Hypertropia } \\
\mathrm{n} . \mathrm{k} . & =\text { not known }
\end{aligned}
$$

cases had post-traumatic detachment following penetrating injury, intra-ocular foreign body or dislocated lens. Four had giant retinal tears, in one case bilaterally. Two had a history of congenital cataract. Five had undergone previous unsuccessful strabismus surgery. All cases had a minimum of one year since their last detachment surgery.

In 17 cases the presenting symptom was poor cosmesis and in 14 the problem was diplopia. In addition there were supplementary complaints of distortion in two patients and glare in one patient.
Visual acuity in the injected eye is shown in Table II. It will be seen that half the series had visual acuity in the injected eye less than $6 / 60$, just over a quarter had $6 / 60$ vision and just under a quarter had vision better than $6 / 60$. It is clear that the cosmetic group had poorer vision, but notable that even in patients with poor foveal function, diplopia may be a major symptom.

Pre-operative motility examination showed that 14 cases were esotropic with a range of $18-50$ prism dioptres and a mean of $30 \mathrm{PD}$ Sixteen cases were exotropic, with a range of 
Table II Visual acuity

\begin{tabular}{ccccl}
\hline & Diplopic & Cosmetic & Total & \\
\hline NPL & & 1 & 1 & \\
PL & & 2 & 2 & $<6 / 60-50 \%$ \\
HM & 1 & 4 & 5 & $=6 / 60-26.6 \%$ \\
CF & 1 & 3 & 4 & $>6 / 60-23.4 \%$ \\
$1 / 60$ & 2 & 1 & 3 & \\
$6 / 60$ & 4 & 4 & 8 & \\
$6 / 36$ & & 1 & 1 & \\
$6 / 24$ & 2 & 1 & 3 & \\
$6 / 12$ & 2 & & 2 & \\
$6 / 9$ & 1 & & 1 & \\
n.k. & 1 & & 1 & \\
\hline
\end{tabular}

12-60 PD and a mean of 36 PD. Two cases of vertical strabismus were treated. Case 1 had 12 PD exotropia and 20 PD right hypertropia and had injection of right lateral and superior recti on the same occasion. Case 4 had a 50 PD right hypotropia.

Pre-operatively the binocular vision status was investigated with prism, synoptophore and stereo tests. In six cases there was unequivocal evidence of good binocular vision, in eight there was poor or dubious binocularity and in 17 cases no binocular vision potential was detected.

\section{Treatment}

All cases were treated with intramuscular injection of purified Botulinum Neurotoxin A in isotonic saline in a volume of $0.1 \mathrm{ml}$. All injections were performed with continuous EMG monitoring with audible and visible displays of the signal. A Medelec MS6 amplifier/ recorder and 27-gauge monopolar electrodes were used throughout.

Case 1 had two injections of US-produced toxin from Dr Alan Scott's laboratory at a concentration of 312 picograms in $0.1 \mathrm{ml}$. Case 2 had three injections of US toxin in the 312 picogram dose and one injection of 1,560 picograms. All other injections in this series were of UK-produced toxin from the laboratory of Professor J. Melling, CAMR, Porton Down. All doses were 62.5 picograms in $0.1 \mathrm{ml}$ of isotonic saline. Sixty-seven injections were given to the 31 patients. The number of injections per patient is shown in Table III. One case (No. 4) proved technically impossible in that an EMG signal could not he obtained so no toxin was administered.
Results-Tables IIIa and IIIb

Four cases-numbers 28-31-have been excluded because of short follow-up. The remainder are divided into a 'diplopia' group and a 'cosmetic' group. In the diplopia group, four of 11 were shown to have no fusion potential because of macular distortion and no further treatment was advised. Two cases had temporary partial improvement and later had surgery. One case had attempted injection but no EMG could be obtained and no injection was given.

Four cases (Nos. 5, 6, 11, 20) had their deviation eliminated and fusion restored. In two cases the realignment was stable. Case 5 continues to have injections at approximately yearly intervals to maintain her alignment. Case 11 elected for surgery 17 months after toxin treatment.

In the cosmetic group of 16 patients two had no useful effect from toxin injection, three had temporary reduction in the deviation but later surgery, three were aligned long-term, and eight continued to attend the Toxin Clinic for maintenance therapy to improve cosmesis. One (Case 2) has since had surgery as an alternative after five years of toxin treatment.

Complications were minor and transient. Ptosis occurred after three injections and subconjunctival haemorrhage after two injections.

\section{Discussion}

In this study we have reviewed 31 patients who underwent a total of 67 previous retinal detachment procedures. Sixty-seven injections of Botulinum toxin were attempted, although in one patient no EMG signal was obtained and no injection given. What benefit was experienced by the use of this agent?

In the diplopia group four cases were shown to have no potential for binocular vision, thereby informing both surgeon and patient that further attempts to straighten the eyes would not relieve diplopia. A further four cases were shown to have good fusion. Two remained stable, one had surgery and one has yearly injections to maintain a controllable phoria. In the cosmetic group three cases were aligned long-term. One regained fusion; one was a woman of 73 . Eight cases have opted for maintenance therapy in the clinic as 
Table IIIa 'Diplopic' group

\begin{tabular}{|c|c|c|c|c|c|}
\hline Case & Deviation & Injections & Compl & $\begin{array}{l}\text { Final } \\
\text { deviation }\end{array}$ & Outcome \\
\hline 4. & $50 \mathrm{R}$ hypo & Failure & - & 50 R hypo & Surgery RIR and LSR \\
\hline 5. & $45 \mathrm{ET}$ & $\times 4 \mathrm{LMR}$ & $\mathrm{SCH}$ & $10 \mathrm{ET}$ & Continued BTXA-BSV \\
\hline 6. & $25 \mathrm{XT}$ & $\times 1 \mathrm{RLR}$ & - & $10 \mathrm{XP}$ & Fusion restored \\
\hline 7. & $35 \mathrm{XT}$ & $\times 2$ LLR & - & Small ET & No BSV-discharged \\
\hline 9. & $40 \mathrm{XT}$ & $\times 1 \mathrm{RLR}$ & $\mathrm{SCH}$ & $40 \mathrm{XT}$ & No BSV-discharged \\
\hline 11 & $18 \mathrm{ET}$ & $\times 1 \mathrm{LMR}$ & - & Straight & Fusion restored \\
\hline 14. & $30 \mathrm{ET}$ & $\times 1 \mathrm{LMR}$ & - & ET/XT & Variable fusion \\
\hline 16. & $35 \mathrm{XT}$ & $\times 1$ LLR & - & $8 \mathrm{ET}$ & No BSV-discharged \\
\hline 18. & $45 \mathrm{XT}$ & $\times 1 \mathrm{RLR}$ & - & $10 \mathrm{XT}$ & Surgery RMR and RLR \\
\hline 20. & $25 \mathrm{ET}$ & $\times 1 \mathrm{RMR}$ & - & Straight & Fusion restored \\
\hline 27. & $43 \mathrm{XT}$ & $\times 1 \mathrm{RLR}$ & - & ET/XT & Improved cosmesis \\
\hline
\end{tabular}

Table IIIb 'Cosmetic' group

\begin{tabular}{|c|c|c|c|c|c|}
\hline Case & Deviation & Injections & Compl & $\begin{array}{l}\text { Final } \\
\text { deviation }\end{array}$ & Outcome \\
\hline \multirow[t]{2}{*}{1.} & $20 \mathrm{RHT}$ & $\times 1 \mathrm{RSR}$ & \multirow[t]{2}{*}{ Ptosis } & $10 \mathrm{RHT}$ & \multirow[t]{2}{*}{ Later surgery } \\
\hline & $12 \mathrm{RXT}$ & $\times 1 \mathrm{RLR}$ & & $8 \times \mathrm{XT}$ & \\
\hline 2. & $45 \times \mathrm{XT}$ & $\times 13$ LLR & - & $10 \mathrm{XT}$ & Maintenance -4 years \\
\hline 3. & $40 \mathrm{XT}$ & $\times 2 \mathrm{LLR}$ & - & $40 \times \mathrm{T}$ & No useful effect \\
\hline 8. & $25 \mathrm{ET}$ & $\times 4 \mathrm{RMR}$ & - & Small XT & Maintenance -4 years \\
\hline 10. & $18 \mathrm{ET}$ & $\times 1 \mathrm{LMR}$ & - & Straight & Discharged \\
\hline 12. & $50 \mathrm{ET}$ & $\times 1 \mathrm{RMR}$ & Ptosis & $30 \mathrm{ET}$ & Later surgery \\
\hline 13. & $45 \mathrm{ET}$ & $\times 6 \mathrm{LMR}$ & - & $10 \mathrm{ET}$ & Maintenance -3 years \\
\hline 15. & $25 \mathrm{ET}$ & $\times 1 \mathrm{LMR}$ & - & $10 \mathrm{EP}$ & Fusion restored \\
\hline 17. & $35 \times \mathrm{T}$ & $\times 2 \mathrm{LLR}$ & - & $10 \times \mathrm{T}$ & Improved \\
\hline 19. & $20 \mathrm{ET}$ & $\times 1 \mathrm{LMR}$ & Ptosis & $10 \times T$ & No useful effect \\
\hline 21. & $45 \mathrm{XT}$ & $\times 3 \mathrm{LLR}$ & - & $8 \mathrm{XT}$ & Maintenance -1.5 years \\
\hline 22. & $25 \mathrm{ET}$ & $\times 6 \mathrm{RMR}$ & - & $\mathrm{ET} / \mathrm{XT}$ & $\begin{array}{l}\text { Maintenance-1 year } \\
\text { Cyclic esotropia }\end{array}$ \\
\hline 23. & $18 \mathrm{XT}$ & $\times 4 \mathrm{RMR}$ & - & $\mathrm{ET} / \mathrm{XT}$ & Maintenance -1 year \\
\hline 24. & $60 \mathrm{XT}$ & $\times 3 \mathrm{RLR}$ & - & $20 \times \mathrm{XT}$ & Maintenance-1 year \\
\hline 25. & $35 \mathrm{XT}$ & $\times 4 \mathrm{LLR}$ & - & $\mathrm{ET} / \mathrm{XT}$ & Maintenance-1 year \\
\hline 26. & $35 \mathrm{ET}$ & $\times 1 \mathrm{LMR}$ & - & $4 \mathrm{ET}$ & Surgery offered \\
\hline
\end{tabular}

Abbreviations: ET $=$ Esotropia

$\mathrm{XT}=$ Exotropia

$\mathrm{HT}=$ Hypertropia

$\mathrm{MR}=$ Medial rectus

$$
\begin{aligned}
\mathrm{LR} & =\text { Lateral rectus } \\
\mathrm{SR} & =\text { Superior rectus } \\
\mathrm{BSV} & =\text { Binocular single vision } \\
\mathrm{SCH} & =\text { Sub-conjunctival haemorrhage }
\end{aligned}
$$

an acceptable alternative to surgery. This last group had typically poor visual acuity in the injected eye, large angles of squint and a history of multiple detachment and strabismus surgery. Their characteristics are shown in Table IV.

In 19 of 31 patients, therefore, toxin treatment provided some benefit. It should also be remembered that toxin therapy is particularly suitable for other reasons. Patients are treated as out-patients under local anaesthesia and do not require admission or surgery. Explants are not disturbed or exposed and the risk of extrusion or redetachment is zero. Minimal discomfort is experienced and the treatment may be repeated at will. We have found a high level of patient acceptibility. Case 2 is a good example of this; he had a total of 13 injections to control a 45 prism dioptre exotropia over four years but requested surgery as an alternative when he moved house and found attendance at the toxin clinic inconvenient.

Scott ${ }^{12}$ has recently reported his experience with Botulinum toxin in strabismus following retinal detachment surgery. He treated 20 
Table IV Cosmetic maintenance group

\begin{tabular}{|c|c|c|c|c|}
\hline Case & Acuity & Deviation & Previous surgery & Other features \\
\hline 2. & $1 / 60$ & $45 \times \mathrm{T}$ & $2 \times$ retinal & IOFB \\
\hline 8. & H.M. & $25 \mathrm{ET}$ & $\begin{array}{l}2 \times \text { retinal } \\
1 \times \text { squint }\end{array}$ & Traumatic lens dislocation \\
\hline 13. & $6 / 60$ & $45 \mathrm{ET}$ & $5 \times$ retinal & Cong. cataracts and schisis \\
\hline 21. & H.M. & $45 \times \mathrm{T}$ & $2 \times$ retinal & Traumatic cataract \\
\hline 22. & N.P.L. & $25 \mathrm{ET}$ & $1 \times$ retinal & Giant tear \\
\hline 23. & P.L. & $18 \mathrm{ET}$ & $\begin{array}{l}3 \times \text { retinal } \\
2 \times \text { squint }\end{array}$ & \\
\hline 24. & $6 / 60$ & $60 \times \mathrm{T}$ & $\begin{array}{l}2 \times \text { retinal } \\
1 \times \text { squint }\end{array}$ & Bilateral giant tear \\
\hline 25. & H.M. & $35 \mathrm{XT}$ & $4 \times$ retinal & Diabetic proliferative retinopathy \\
\hline
\end{tabular}

patients, five of whom had more than one detachment operation. Four of these five had also had unsuccessful strabismus surgery.

Vision was much better in his patients. Three had $6 / 60$ vision and one had 3/60. All the remainder were better than this. He obtained restoration of fusion and elimination of diplopia in 12 of 20 patients. Of the five patients with persistent diplopia two were cases of multiple retinal and strabismus surgery and two had vertical deviations induced by medial rectus injection.

One might speculate on the mechanism of action in these cases. Usually at surgery these patients have extensive scarring and adhesions, and may have positive forced duction tests. Nevertheless, a reduction of the angle can be seen following almost every injection. Clearly we must revise our concepts of the underlying pathology in 'restrictive' strabismus. The recent paper by Lyons and colleagues $^{13}$ on the use of botulinum toxin in dysthyroid strabismus suggests that in some cases of 'restrictive' strabismus an active reversible contracture is taking place and that it is this component which is affected by botulinum toxin therapy.

We conclude that intramuscular injection of Botulinum toxin is a practicable management of strabismus following retinal detachment surgery. It may make further strabismus surgery unnecessary and may have particular value in cosmetic maintenance therapy in younger patients with poor vision after complex retinal surgery.
References

${ }^{1}$ Portney GL, Campbell LH, Casebeer JC: Acquired heterotropia following surgery for retinal detachment. Am J Ophthalmol 1972, 73: 985-90.

${ }^{2}$ Kanski JJ, Elkington AR, Davies MS: Diplopia after retinal detachment surgery. Am J Ophthalmol 1973, 76: $38-40$.

${ }^{3}$ Sewell JJ, Knobloch WH, Eifrig DE: Extraocular muscle imbalance after surgical treatment for retinal detachment. Am J Ophthalmol 1974, 78: 321-3.

${ }^{+}$Price RL and Pederzolli A: Strabismus following retinal detachment surgery. Am Orthopt J 1982, 32: 9-17.

${ }^{5}$ Waddell E: Retinal detachment and orthoptics. $\mathrm{Br}$ Orthopt J 1983, 40: 5-12.

${ }^{6}$ Mets MB, Wendell ME, Gieser RG: Ocular deviation after retinal detachment surgery. $A m \mathrm{~J}$ Ophthalmol 1985, 99: 667-72.

${ }^{7}$ Smiddy WE, Loupe D, Michels RG, Enger C, Glaser BM, de Bustros S: Extraocular muscle imbalance after scleral buckling surgery. Ophthalmology 1989, 96: 1485-90.

${ }^{8}$ Fells P and Lee J: Management of strabismus following surgery for retinal detachment. Trans Eur Strabmismol Assoc 1984, 1984: 207-14.

${ }^{9}$ Fison PN and Chignell AH: Diplopia after retinal detachment surgery. Br J Ophthalmol 1987, 71: 521-5.

${ }^{10}$ Wright KW: The fat adherence syndrome and strabismus after retina surgery. Ophthalmology 1986, 93: 411-15.

${ }^{11}$ Munoz M and Rosenbaum AL: Longterm strabismus complications following retinal detachment surgery. J Ped Ophthalmol and Strabism 1987, 24: 309-14.

${ }^{12}$ Scott AB: Botulinum treatment of strabismus following retinal detachment surgery. Arch Ophthalmol 1990, 108: 509-10.

${ }^{13}$ Lyons CJ, Vickers SF, Lee JP: Botulinum toxin therapy in dysthyroid strabismus. Eye 1990, 4: $538-40$. 